
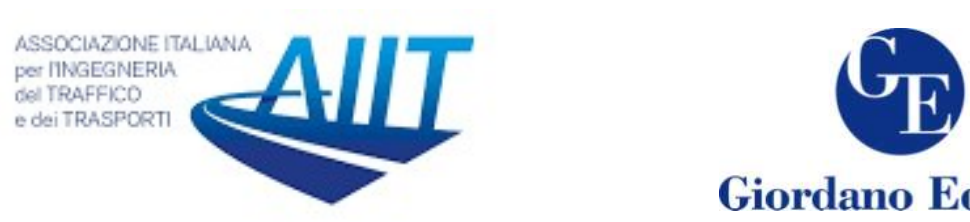

Giordano Editore

\title{
A probabilistic approach for permissive left turns from shared lanes at two-stage traffic signals
}

\author{
Belkheir Wissem ${ }^{1 *}$, Boumediene Ahmed ${ }^{2}$, Brahimi Kouider ${ }^{3}$ \\ (1) (2) (3) Université des Sciences et de la Technologie d'Oran-Mohamed Boudiaf \\ BP 1505El-Menouar 31000 Oran, Algeria
}

\begin{abstract}
Left-turning movements affect considerably the capacity of traffic signal controlled intersections, especially, when there is no separate left-turn lane and vehicles wishing to turn left must share the same lane with straight ahead traffic and the same green stage with an opposing flow. In such a case the capacity is influenced by a number of traffic and geometrical parameters.

As flow levels and experience have increased over the years, methods and means have been developed to cope with the growing traffic demand. As volumes increase, the need for protecting left-turners increases also. The models are based on a diversity of assumptions and each has some limitations when applied in practice. In addition, all models, but a few, don't account for possible spaces existing within the intersection area for left turner to be stored without blocking straight ahead vehicles sharing the same lane.

This paper presents a probabilistic model developed for calculating the capacity of shared left-turn lanes with an opposing traffic flow at traffic signals controlled intersections. It was validated by field data collected at six sites with 1, to 5 spaces available for left-turners seeking suitable gaps in the opposing flow without blocking the progression of straight through vehicles.
\end{abstract}

Keywords: Signalised intersections, permissive left turns, shared lanes, capacity, Traffic engineering.

\section{Background and literature review}

Intersections are singular nodes of road network that affect considerably its capacity. Hence, a particular attention should be paid for their treatment in terms of geometrical layout as well as in terms of control and operation in order to improve capacity with lesser delay and minimum conflicts. Intersections are key elements of traffic control and management of road network. The majority of conflicts between vehicles, between vehicles and pedestrians, take place within intersections particularly in urban areas inducing saturation situations, delays to road users and accidents, and this may provoke a degradation of traffic and security conditions. A better analysis of such conflicts helps dealing with traffic flowing and having a more precise idea on how to handle the problems

\footnotetext{
* Corresponding author: Belkheir Wissem ( wiss.gc@live.fr)
} 
raised and to decide on the adequate solutions which improve capacity and allow (necessary) turning movements to take place safely (D. Županović, M. Anžek, G. Kos 2010). This helps choosing the appropriate geometrical layouts, traffic control and management systems.

Depending on traffic flows levels and allowed movements, the number and frequency of conflicts within the intersection can be, easily, dealt with or can induce conflicting situations that may bring about saturation conditions in the intersection, even provoking accidents.

Road effectiveness depends on junctions' capacity to handle the traffic to be evacuated with lesser delays and a minimum of conflicts. This is particularly important for normal two-stage signal phasing where all permissive left-turners face conflicts with the opposing flow as both share the same green stage. A more complex problem is that resulting when a traffic stream made-up of left-turners and straight-ahead (or right-turners) vehicles sharing the same lane must share also the same green stage with an opposing flow; in such a case any vehicle turning left creates, in succession, the three basic main conflicts: (i) a divergence while leaving the original stream, (ii) a crossing when passing through suitable gaps in the opposing stream, and (iii) a convergence when merging with the exit stream made up with right turners from the opposing stream. In this case, they decrease considerably the capacity and increase delays and the risk of accidents.

The most common and usually desirable practice is to dedicate a separate lane to segregate conflicting movements to allow through vehicles to proceed without interference (W. Wu et al 2015). If the provision of a separate lane cannot be met a second solution is to widen the intersection approach to form a left-turn slip pocket (AntanasKlibavičius and GražvydasMykolasPaliulis 2012) in order to provide the best traffic operation and control for capacity and safety purposes. However, in many cases neither providing a separate lane nor widening the entry can be possible at will, particularly in built (urban) areas, and one lane must be shared between traffic turning left and traffic proceeding straight ahead.

At traffic signals, separate phasing can also be used to protect an opposed movement that will, otherwise, be impeded, and even blocked. It allows a smoother traffic flow, improves the opposed movement capacity and reduces accidents. However, it has negative side effects too since the overall intersection capacity decreases and total delay increases because of the portion of cycle time taken up to accommodate the opposed movement and the lost time due to the extra inter-green period. Separate phasing is, therefore, not possible in many situations and left-turn movements must share the same green stage with the opposing flow. In such circumstances, depending on the proportion of left-turners in the shared lane and the degree of saturation of the opposing flow; the capacity of a shared lane, during a cycle time, varies from almost zero (plus sneakers during the inter-green) to a level equivalent to that of a lane dedicated exclusively for a straight-ahead stream. In China, transportation professionals use left-turn waiting areas usually set up beyond the stop line at an exclusive left-turn lane or dual left-turn lanes to improve traffic efficiency (Zhao Yang, Pan Liu, Zong Z. Tian, and Wei Wang 2012). The results indicate that the capacity would increase with increasing storage capacity of the left-turn waiting area.

As flow levels and experience increased over the years, methods and means have been developed to cope with the growing traffic demand. With volumes increase, the need for 
protecting left-turners increases also. To deal with such situations different models have been developed for calculating the capacity of left-turning traffic flows from, both exclusive and shared, left-turn lanes. These models are based on a variety of assumptions and each has some limitations when applied in practice. The differences observed between actual and estimated capacities suggest that there is still room for further investigations. This is particularly observed in Algeria who experienced a very rapid growth of car ownership level which has almost doubled in a decade period as a consequence of oil price increase and higher living standards, making traffic control, management and operation one of the major concerns for both the population and public authorities as the existing road network is insufficient, particularly, in city centres where the majority of streets are only 6-7 meters wide. Engineering and design offices face a problem since there is no Algerian official manual dealing with signalized intersections studies and only foreign methods are used, without checking their appropriateness for Algerian context. The model presented hereafter is part of a research project, currently in progress, aimed at elaborating a capacity guide for signalised intersections in Algerian traffic and environment prevailing conditions.

The main objective of this paper is to compare the capacities data obtained from field observations with those estimated by means of the HCM (Highway Capacity Manual) method and a theoretical model developed by the authors and look to what extent they can represent satisfactorily actual capacity of permissive left-turns at intersections controlled by traffic signals.

Traditional methods for traffic capacity assessment account for left turners' effect, in general, by means of a weighing factor to convert them to straight ahead vehicles equivalent. More elaborated manuals relate these equivalent factors to geometric features of the intersection and traffic characteristics and/or intersection location (Kimber, R.M et al1986), (Teply et al 2008), (Yao R. and Michel Zhang H 2013). However, they do not account sufficiently neither for the reduction of capacity of shared lanes nor for the possibility that a number of straight ahead vehicles can proceed through the intersection until a left turner arrives and blocks the movement. This problem seems to have been first investigated (theoretically) by Bang (Bang, K.L 1978) in the Swedish capacity manual who presented two equations for, respectively, the cases where the first or the second left turner in the queue blocks the movement. The case of the first left turner blocking the lane was embodied in the HCM 1985 edition (Transportation Research Board 1985). The HCM 2010 edition method (Transportation Research Board 2010) accounts for left turning movements blockage using regression formulae based on observations for calculating "the time that elapses from the start of the permitted green to the arrival of the first left turning vehicle at the stop line" with an upper limit equal to the saturated period of the opposing stream (equations 1 and 2). However, in chapter 31/signalised intersections: supplemental of July 2012, this upper limit is computed with a formula deduced from that already embodied in the HCM 1985 edition for the case of the first left turner blocking the lane (equation 4).

If the approach has one lane, then:

$$
g_{f}=\max \left(G_{p} e^{-0.860 L_{T C}^{0.629}}-l_{1, p}, 0.0\right) \leq g_{f, \max }
$$

Otherwise 


$$
g_{f}=\max \left(G_{p} e^{-0.882 L^{2 T C} C^{0.717}}-l_{1, p}, 0.0\right) \leq g_{f, \max }
$$

With

Where

$$
\mathrm{LTC}=\frac{\mathrm{v}_{\mathrm{lt}} \mathrm{C}}{3600}
$$

$\mathrm{g}_{\mathrm{f}}=$ time before the first left turning vehicle arrives and blocks the shared lane(s), $G_{p}=$ displayed green interval corresponding to $g_{p}(s)$,

LTC $=$ left turn flow rate per cycle (veh/cycle),

$\mathrm{l}_{1, \mathrm{p}}=$ permitted start-up lost time $(\mathrm{s})$,

$\mathrm{v}_{\mathrm{lt}}=$ left turn demand flow rate $(\mathrm{veh} / \mathrm{h})$, and

$\mathrm{C}=$ cycle length $(\mathrm{s})$.

Where:

$$
\mathrm{g}_{\mathrm{f}, \max }=\frac{\left(1-\mathrm{P}_{\mathrm{L}}\right)}{0.5 \mathrm{P}_{\mathrm{L}}}\left(1-\left[1-\mathrm{P}_{\mathrm{L}}\right]^{0.5 \mathrm{~g}_{\mathrm{p}}}\right)-\mathrm{l}_{1, \mathrm{p}} \geq 0.0
$$

$\mathrm{g}_{\mathrm{f}, \mathrm{max}}=$ maximum time before the first left turning vehicle arrives and within which there are sufficient through vehicles to depart at saturation (s),

$\mathrm{P}_{\mathrm{L}}=$ proportion of left turning vehicles in the shared lane (decimal),

$\mathrm{g}_{\mathrm{p}}=$ effective green time for permitted left turn operation ( $\mathrm{s}$ );

The value of " 0.5 " represents the approximate saturation flow rate (in vehicles per second) of through vehicles in an exclusive lane. This approximation simplifies the calculation and provides sufficient accuracy in the estimate of.g $\mathrm{g}_{\mathrm{f}, \mathrm{max}}$.

This is the main weakness of the north American method, since, ignoring the possibility of having a number of spaces where left turning vehicles can be stored within the intersection in manner which does not impede straight-ahead vehicles in their motion will misestimate the capacity of the lane. In fact, at an early stage of the research work, the authors thought about adopting the HCM 2010 methodology with amendments to take account of Algerian traffic conditions. However, the HCM method does not represent satisfactory field data collected in this work as explained hereafter. However, as shown in figure 1 (for data collected in this project) the north American Highway Capacity Manual method does not satisfactorily estimate the capacity of shared lanes in the case of intersections with layouts providing two or more spaces for queuing left turners. The discrepancies between observed and calculated capacities are statistically significant at the $95 \%$ level of confidence. 


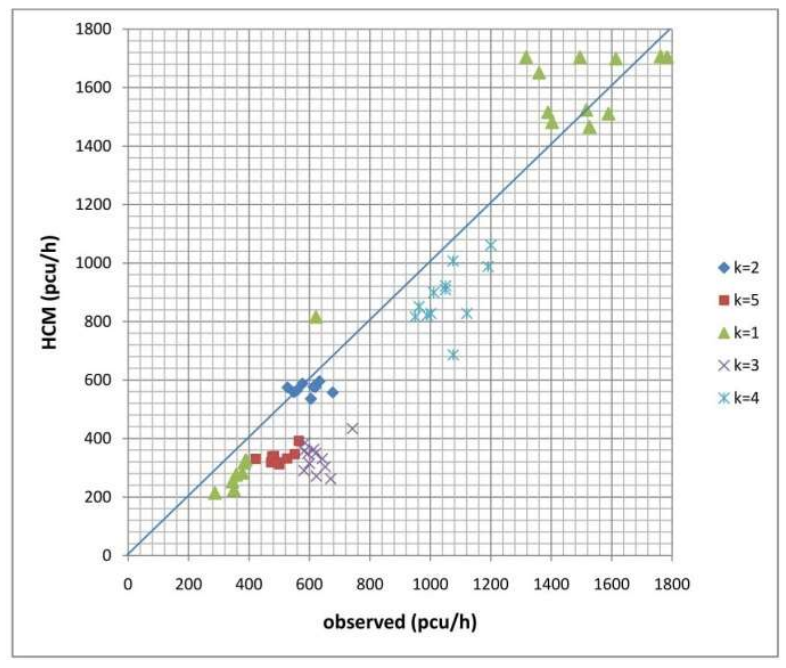

Figure 1: Observed vs. HCM 2010 saturation flows.

Some researchers developed more elaborated models to deal with the blockage of permitted left turning from shared lanes at traffic signal controlled intersections. Wu N. (2010) reported that the German Highway Capacity Manual (HBS 2001) ignores completely the capacity reduction of shared lanes. He developed a mathematical model to quantify the influence of permitted turning vehicles (either left-turn or right-turn movements) on the total capacity of shared lanes at fixed time controlled and isolated intersections. However, he indicated in his paper that the equation proposed cannot be solved analytically and thus, it is not applicable in practice, and he then presented a set of monographs and approximation functions that can be used for practical applications. Brahimi K. (1989) and Brahimi K. \& Ashworth R. (1992) extended Bang's model to more spaces available within the intersection for waiting left turners.

\section{The proposed model for permissive left turns from shared lanes}

\subsection{Assumptions and notations}

Left-turns, either from shared lanes or exclusive lanes, have a complex impact on intersection operations. The movement can be broken down into three basic consecutive stages as shown in figure 2 .

- The first stage starts as the green signal shows until the queue is blocked on the subject lane by an extra left turner,

- The second stage begins after the opposing queue vanishes and waiting left turners can pass through suitable gaps in the opposing stream allowing straight ahead vehicles in the shared lane to move forward.

- The third stage corresponds to the inter-green period during which the still waiting left turners clear the intersection. 


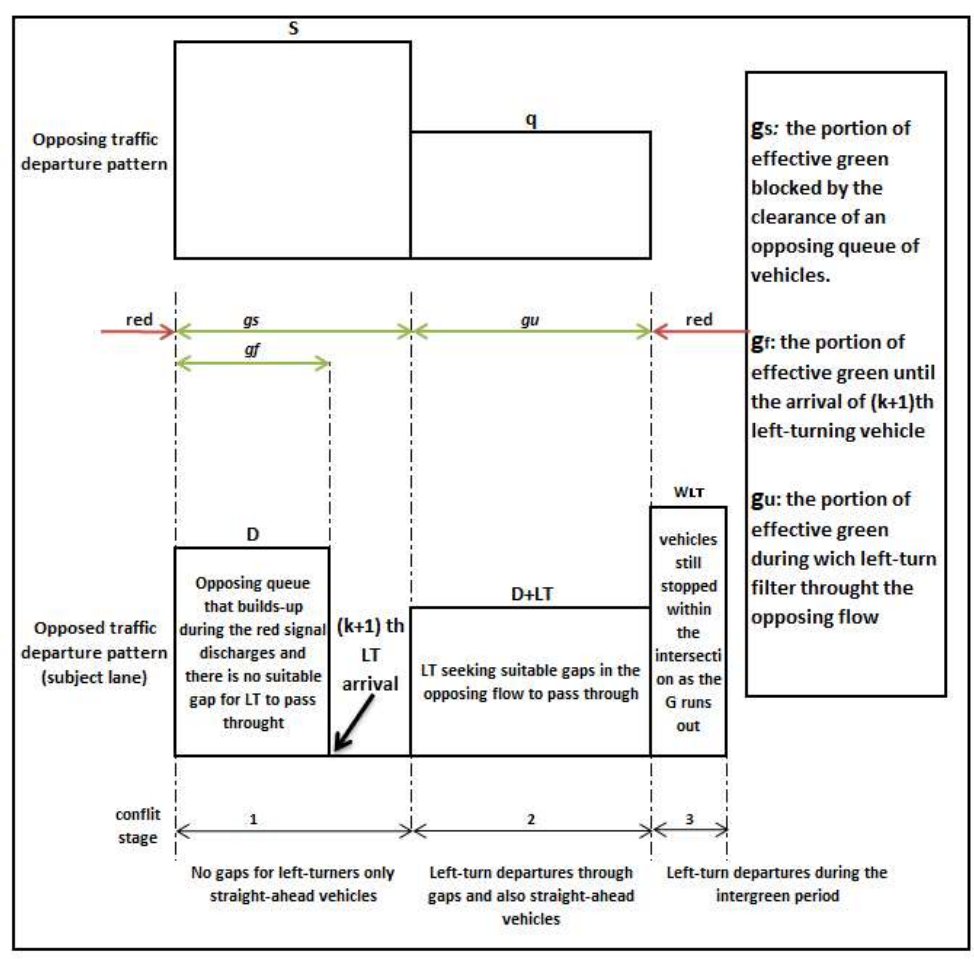

Figure 2: Shared lane opposed left turn model

The model was built up from simple probability considerations under a set of assumptions among which the followings:

- Signal settings operate on a fixed basis and are known in advance,

- Completely random arrivals are assumed on the opposing approach, yielding a negative exponential distribution of headways between consecutive vehicles,

- The opposing queue discharges at a constant rate $\mathrm{s}(\mathrm{veh} / \mathrm{sec})$ during a period $\mathrm{g}_{\mathrm{S}}$ second

$$
\mathrm{g}_{\mathrm{S}}=\frac{\mathrm{q}(\mathrm{c}-\mathrm{g})}{\mathrm{s}-\mathrm{q}}
$$

Where

$\mathrm{c}$ and $\mathrm{g}$ are respectively cycle and effective green times in seconds and

$\mathrm{s}$ and $\mathrm{q}$ are respectively saturation and actual flows for the opposing stream in $\mathrm{veh} / \mathrm{sec}$,

- On the subject arm the opposed traffic stream is made up of left turners and straight ahead vehicles, binomially distributed $\left[\mathrm{P}(\mathrm{x}=\mathrm{k})=\mathrm{C}_{\mathrm{N}}^{\mathrm{k}} \mathrm{p}^{\mathrm{k}} \times(1-\mathrm{p})^{\mathrm{N}-\mathrm{k}}\right]$ with $\mathrm{p}$ left turners and $\mathrm{q}(=1-\mathrm{p})$ straight ahead, $\mathrm{p}$ being the proportion of left turners in the movement under consideration,

- $\mathrm{k}$ spaces are available within the intersection (beyond the stop line) for left turners to queue without blocking the lane for following vehicles. The $(\mathrm{k}+1)$ th left turner blocks the lane, until an acceptable gap appears in the opposing traffic stream.

- Waiting left turners require a constant accepted critical gap $\alpha$ and a follow up headway $\beta$ during the unsaturated period $g_{u}\left(=g_{-} g_{S}\right)$ on the opposing arm, and the discharge rate of the waiting left turn queue 
- The opposed stream, in the shared lane, discharges at a constant rate $\mathrm{s}$ as long as vehicles are not impeded in their movement, and so the maximum number of vehicles $\mathrm{N}$ discharging from the subject lane (i.e. if there were only straight ahead vehicles) is

$$
\mathrm{N}=\mathrm{g}_{\mathrm{S}} \cdot \mathrm{s}
$$

\subsection{Model formulation}

From simple probability theory (table 1) one can derive the model formulae for the first stage (equations 7-9) (table2).

Table 1.Probability Basic Elements

\begin{tabular}{|c|c|c|c|c|c|c|}
\hline No.of LT/cycle & probability & $\begin{array}{c}\text { No of LT } \\
\text { stored }\end{array}$ & $\begin{array}{c}\text { Ahead } \\
\text { capacity }\end{array}$ & $\begin{array}{c}\text { Total } \\
\text { capacity }\end{array}$ & \multicolumn{2}{|c|}{ No. of combinations } \\
\hline 0 & $p^{0} q^{N}$ & 0 & $N$ & $N$ & $C_{N}^{0}$ & \multirow{6}{*}{ 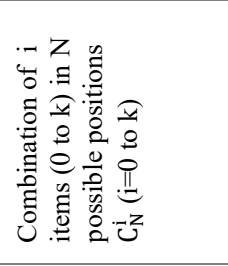 } \\
\hline 1 & $p^{1} q^{N-1}$ & 1 & $N-1$ & $N$ & $C_{N}^{1}$ & \\
\hline 2 & $p^{2} q^{N-2}$ & 2 & $N-2$ & $N$ & $C_{N}^{2}$ & \\
\hline . & - & & - & - & & \\
\hline . & - & & - & - & & \\
\hline$K L T$ & $p^{k} q^{N-k}$ & $k$ & $N-k$ & $N$ & $C_{N}^{k}$ & \\
\hline$K+1$ (or more) LT per cycle & & & & & & \multirow{7}{*}{ 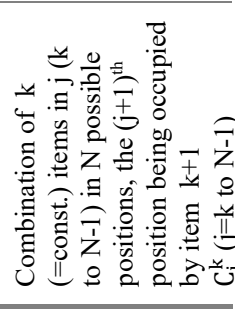 } \\
\hline With $(k+1)$ th in $(k+1)$ th position & $p^{k+1} q^{0}$ & $k+1$ & 0 & $k+1$ & $C_{k}^{k}$ & \\
\hline$(k+2) t h$ & $p^{k+1} q^{1}$ & - & 1 & $k+2$ & $C_{k+1}^{k}$ & \\
\hline$(k+3) t h$ & $p^{k+1} q^{2}$ & $k+1$ & 2 & $k+3$ & $C_{k+2}^{k}$ & \\
\hline . & - & - & - & - & & \\
\hline . & - & - & - & - & & \\
\hline$(N) t h$ & $p^{k+1} q^{N-k-1}$ & $k+1$ & $N-k-1$ & $N$ & $C_{N-1}^{k}$ & \\
\hline
\end{tabular}

$N=$ maximum number of vehicles/ cycle; $k=$ storage spaces for left-turners; $p=$ proportion of left-turners; $q=(1-p)=$ proportion of straight-ahead vehicles

Table 2. Derivation of the formula of capacity

\begin{tabular}{|c|c|c|c|c|c|}
\hline Situation & $\begin{array}{l}\text { Sequence across the stop line } \\
\begin{array}{l}1 \\
2\end{array} 3 \ldots \ldots \ldots \ldots \ldots . . \ldots \ldots \ldots \ldots \ldots \ldots \ldots . . .\end{array}$ & probability & $\begin{array}{l}\text { No of } \\
\text { LT }\end{array}$ & $\begin{array}{l}\text { No of } \\
\text { Ahead }\end{array}$ & $\begin{array}{c}\text { Total } \\
\text { No }\end{array}$ \\
\hline $0 L T$ & 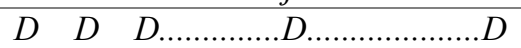 & $p^{0} q^{N}$ & 0 & $N$ & $N$ \\
\hline $1 L T$ & $\ldots \ldots D \ldots \ldots \ldots \ldots \ldots \ldots \ldots$ & $p^{1} q^{N-1}$ & 1 & $N-1$ & $N$ \\
\hline . & 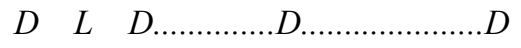 & - & - & - & - \\
\hline . & $D \quad D \quad D \ldots \ldots \ldots \ldots . D \quad L \ldots \ldots \ldots \ldots \ldots D$ & - & - & - & - \\
\hline . & $D \quad D \quad D \ldots \ldots \ldots \ldots \ldots \ldots \ldots \ldots \ldots \ldots \ldots . . . L$ & $p^{1} q^{N-1}$ & 1 & $N-1$ & $N$ \\
\hline $2 L T$ & ......D.................D & $p^{2} q^{N-2}$ & 2 & $N-2$ & $N$ \\
\hline . & 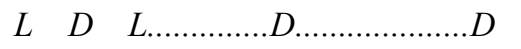 & - & & - & - \\
\hline . & 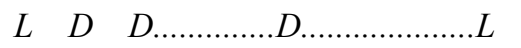 & - & & - & - \\
\hline . & $D \quad D \quad D \ldots \ldots \ldots \ldots \ldots \ldots \ldots \ldots \ldots L L$ & $p^{2} q^{N-2}$ & 2 & $N-2$ & $N$ \\
\hline$K L T$ & $L \quad L \quad D \ldots \ldots L \ldots \ldots D \ldots \ldots \ldots \ldots \ldots \ldots$ & $p^{k} q^{N-k}$ & $k$ & $N-k$ & $N$ \\
\hline . & $D \quad L \quad L \ldots \ldots \ldots \ldots . . \ldots \ldots \ldots \ldots \ldots \ldots \ldots$ & - & - & - & - \\
\hline . & 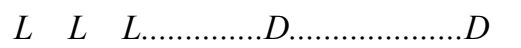 & - & - & - & - \\
\hline . & $D \quad D \quad D \ldots \ldots \ldots \ldots \ldots \ldots \ldots \ldots \ldots \ldots \ldots$ & $p^{k} q^{N-k}$ & $k$ & $N-k$ & $N$ \\
\hline$(K+1) L T$ & $L \quad L \quad . \quad L$ & $p^{k+1} q^{0}$ & $k+1$ & 0 & $k+1$ \\
\hline . & - & - & - & - & - \\
\hline . & - & - & - & - & - \\
\hline - &.$L$ & $p^{k+1} q^{j-k}$ & $k+1$ & $j-k$ & $j+1$ \\
\hline . & - & - & - & - & - \\
\hline
\end{tabular}


\begin{tabular}{lrrrrr}
\hline. & - & - & - & - & - \\
. & $\ldots \ldots \ldots \ldots \ldots \ldots \ldots \ldots \ldots \ldots . \ldots \ldots \ldots \ldots . L$ & $p^{k+1} q^{N-k-1}$ & $k+1$ & $N-k-1$ & $N$ \\
\hline
\end{tabular}

\section{$\underline{\text { From table }}$}

The expected value $\mathrm{D}$ of the number of straight vehicles passing through the intersection before blocking occurs during the first stage $\left(\mathrm{G}_{\mathrm{f}}\right)$ is given by equation (7).

$$
\begin{gathered}
D=N \times p^{0} q^{N}+(N-1) p^{1} q^{N-1} \times(N)+(N+2) p^{2} q^{N-2} \times \frac{N(N-1)}{2}+\cdots(N-k) p^{k} q^{N-k} C_{N}^{k}+ \\
p^{k+1} \sum_{j=k}^{N-1}(j-k) q^{j-k} C_{j}^{k} \\
D=\sum_{i=0}^{k} p^{i} q^{(N-i)}(N-i) C_{N}^{i}+p^{(k+1)} \sum_{j=k}^{N-1}(j-k) q^{j-k} C_{j}^{k}
\end{gathered}
$$

By the end of the discharge of the opposing queue, the expected value of the number of vehicles waiting to turn left within the intersection, beyond the stop line, is given by equation (8),

$$
\begin{gathered}
W=0 \times p^{0} q^{N}+N p^{1} q^{N-1}+2 p^{2} q^{N-2} \times \frac{N(N-1)}{2}+\cdots k p^{k} q^{N-k} C_{N}^{k}+(k+1) p^{k+1} \sum_{j=k}^{N-1}(j-k) q^{j-k} C_{j}^{k} \\
W=\sum_{i=0}^{k} p^{i} q^{(N-i)} i C_{N}^{i}+(k+1) p^{(k+1)} \sum_{j=k}^{N-1} q^{j-k} C_{j}^{k}
\end{gathered}
$$

and hence the expected value $\mathrm{T}(=\mathrm{D}+\mathrm{W})$ of the total number of vehicles crossing the stop line during $\mathrm{G}_{\mathrm{S}}$ is given by equation (9).

$$
\begin{gathered}
T=N \times p^{0} q^{N}+N q^{N-1} \times N+N p^{2} q^{N-2} \times \frac{N(N-1)}{2}+\cdots N \times p^{k} q^{N-k} C_{N}^{k}+p^{k+1} \sum_{j=k}^{N-1}(j+1) q^{j-k} C_{j}^{k} \\
T=\sum_{i=0}^{k} p^{i} q^{(N-i)} N C_{N}^{i}+p^{(k+1)} \sum_{j=k}^{N-1}(j+1) q^{j-k} C_{j}^{k}
\end{gathered}
$$

Where $\quad \mathrm{C}_{\mathrm{N}}^{\mathrm{i}}=\frac{\mathrm{N} !}{\mathrm{i} !(\mathrm{N}-\mathrm{i}) !} \quad \mathrm{C}_{\mathrm{j}}^{\mathrm{k}}=\frac{\mathrm{j} !}{\mathrm{k} !(\mathrm{j}-\mathrm{k}) !}$

Equation (9) can be easily simplified for $\mathrm{k}=0$ to $\mathrm{k}=3$ corresponding to current layouts (table 3).

The sum in equation (9) is a geometrical series and hence it reduces to $\mathrm{T}_{0}$ first equation in table 3 , and the formula found is developed as follows:

$$
\mathrm{T}_{\mathrm{k}}=\sum_{\mathrm{i}=0}^{\mathrm{k}} \mathrm{p}^{\mathrm{i}} \mathrm{q}^{(\mathrm{N}-\mathrm{i})} \mathrm{NC} \mathrm{C}_{\mathrm{N}}^{\mathrm{i}}+\mathrm{p}^{(\mathrm{k}+1)} \sum_{\mathrm{j}=\mathrm{k}}^{\mathrm{N}-1}(\mathrm{j}+1) \mathrm{q}^{\mathrm{j}-\mathrm{k}} \mathrm{C}_{\mathrm{j}}^{\mathrm{k}}
$$

We take $\quad \mathrm{q}=\mathrm{p}-1$

For $\mathrm{k}=0$ we have

$$
\begin{aligned}
& T_{0}=p^{0}(1-p)^{N} N C_{N}^{0}+\sum_{j=0}^{N-1}(j+1)(1-p)^{j} p^{(0+1)} C_{j}^{0} \\
& \text { Where } \quad C_{N}^{0}=\frac{N !}{0 ! N !}=1 \quad \& \quad C_{j}^{0}=\frac{j !}{0 ! j !}=1 \\
& T_{0}=N(1-p)^{N}+p \sum_{j=0}^{N-1}(1-p)^{j}+p \sum_{j=0}^{N-1} j(1-p)^{j}
\end{aligned}
$$




$$
\begin{aligned}
T_{0}=(1- & p)^{N} N+\sum_{j=0}^{N-1}(j+1)(1-p)^{j} p=N(1-p)^{N}+p \sum_{j=0}^{N-1}(j+1)(1-p)^{j} \\
& \sum_{j=0}^{N-1}(1-p)^{j}=\frac{1-(1-p)^{N}}{1-(1-p)}=\frac{1-(1-p)^{N}}{p} \\
& \sum_{j=0}^{N-1} j(1-p)^{j}=\frac{-N(1-p)^{N}+N(1-p)^{N+1}+(1-p)-(1-p)-(1-p)^{N+1}}{p^{2}}
\end{aligned}
$$

If we take $X=1-p$

$$
\begin{aligned}
& \mathrm{T}_{0}=\mathrm{N} \mathrm{X}^{\mathrm{N}}+(1-\mathrm{X})\left[\frac{1-\mathrm{X}^{\mathrm{N}}}{(1-\mathrm{X})}+\frac{\mathrm{X}-\mathrm{X}^{\mathrm{N}+1}-\mathrm{N} \mathrm{X}^{\mathrm{N}}+\mathrm{N} \mathrm{X}^{\mathrm{N}+1}}{(1-\mathrm{X})^{2}}\right] \\
& \mathrm{T}_{0}=\mathrm{N} \mathrm{X}^{\mathrm{N}}+(1-\mathrm{X})\left[\frac{\left(1-\mathrm{X}^{\mathrm{N}}\right)(1-\mathrm{X})+\mathrm{X}-\mathrm{X}^{\mathrm{N}+1}-\mathrm{N} \mathrm{X}^{\mathrm{N}}+\mathrm{N} \mathrm{X}^{\mathrm{N}+1}}{(1-\mathrm{X})^{2}}\right]
\end{aligned}
$$

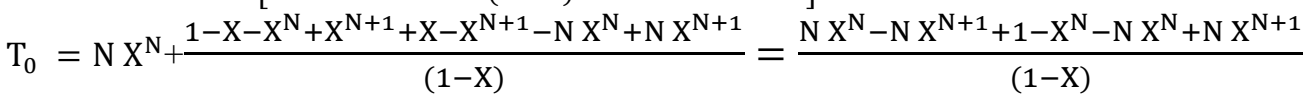

$$
\begin{aligned}
& \mathrm{T}_{0}=\frac{1-\mathrm{X}^{\mathrm{N}}}{(1-\mathrm{X})} \quad \text { so } \quad \mathrm{T}_{0}=\frac{1-(1-\mathrm{p})^{\mathrm{N}}}{\mathrm{p}}
\end{aligned}
$$

We do the same thing to find $\mathrm{T}_{\mathrm{k}}$ for $\mathrm{k}=1,2,3$

Table 3. Simplified expressions for $\mathrm{k}=0$ to $\mathrm{k}=3$

\begin{tabular}{lc}
\hline$k$ & $\frac{1-(1-p)^{N}}{p}$ \\
\hline 0 & $\frac{2}{p}\left[1-(1-p)^{N}\right]-N(1-p)^{N-1}$ \\
2 & $\frac{3}{p}\left[1-(1-p)^{N}\right]+\frac{N(N-5)}{2}(1-p)^{N-1}-\frac{N(N-1)}{2}(1-p)^{N-2}$ \\
3 & $\frac{3}{p}\left[1-(1-p)^{N}\right]+\frac{N(N-5)}{2}(1-p)^{N-1}-\frac{N(N-1)}{2}(1-p)^{N-2}+\frac{N\left(N^{2}-6 N+5\right)}{3}(1-p)^{N-2}$ \\
& $-\frac{N\left(N^{2}-3 N+2\right)}{6}(1-p)^{N-3}$ \\
\hline
\end{tabular}

During the unsaturated period on the opposing arm (designed here as the 2 nd stage), left turners waiting within the intersection seek suitable gaps in the opposing traffic stream to complete their movement and, each time a left turner moves on, the opportunity is given to following vehicles to enter the intersection. The average time interval between successive left turning vehicles is $1 / \mathrm{Su}$, Su being the capacity of left turners through suitable gaps in the opposing stream (equation 10).

$$
\mathrm{S}_{\mathrm{u}}=\frac{\mathrm{qe}^{-\mathrm{q} \alpha}}{1-\mathrm{e}^{-\mathrm{q} \beta}}
$$

and during that time the expected number of vehicles able to cross the stop line from the subject lane is computed by equation 8 above with $\mathrm{k}=0$ which reduces to equation 11 as indicated in table 3.

$$
\frac{1-(1-p)^{N}}{p}
$$


In the case of $\mathrm{N}=0.5 / \mathrm{S}_{\mathrm{u}}$ (assuming one vehicle every 2 seconds across the stop line) the resultant capacity $U$ during the second stage of the conflict is therefore given by equation 12.

$$
\mathrm{U}=\mathrm{g}_{\mathrm{u}} \mathrm{S}_{\mathrm{u}} \frac{1-\mathrm{q}^{0.5 / \mathrm{S}_{\mathrm{u}}}}{1-\mathrm{q}}
$$

During the 3rd stage, (i.e. after the green signal turns off), those waiting left turners (which have already been included in equation 8) are assumed to clear the intersection during the inter-green time period. The total number of vehicles entering the intersection per cycle is therefore $\mathrm{T}+\mathrm{U}$ and the total capacity per hour of the shared lane is.3600 $(\mathrm{T}+$ $\mathrm{U}) / \mathrm{c}$

\subsection{Validation of the model}

The model was tested against an extensive data collection program at 6 sites totalising (51) field surveys part of a research project currently in progress. Each survey lasted for one hour or more during morning and/or evening peak periods with an endless queue in the subject lane for capacity appreciation purpose. The number of spaces for waiting left turners $\mathrm{k}$ within the intersection, without blocking the lane, varied from $\mathrm{k}=1$ to $\mathrm{k}=5$. Different two-phase signal settings operating on fixed time basis were implemented. The proportion of left turners in the subject lane varied from $9 \%$ to $100 \%$. The degree of saturation of the opposing stream varied from $0.38 \%$ to $0.99 \%$. Figure 3 shows the results obtained and it appears that the model satisfactorily estimates the capacity of shared lanes with an opposed flow at traffic signals. A paired t-test was performed and the differences between observed and calculated values were not statistically significant at the $95 \%$ confidence level.

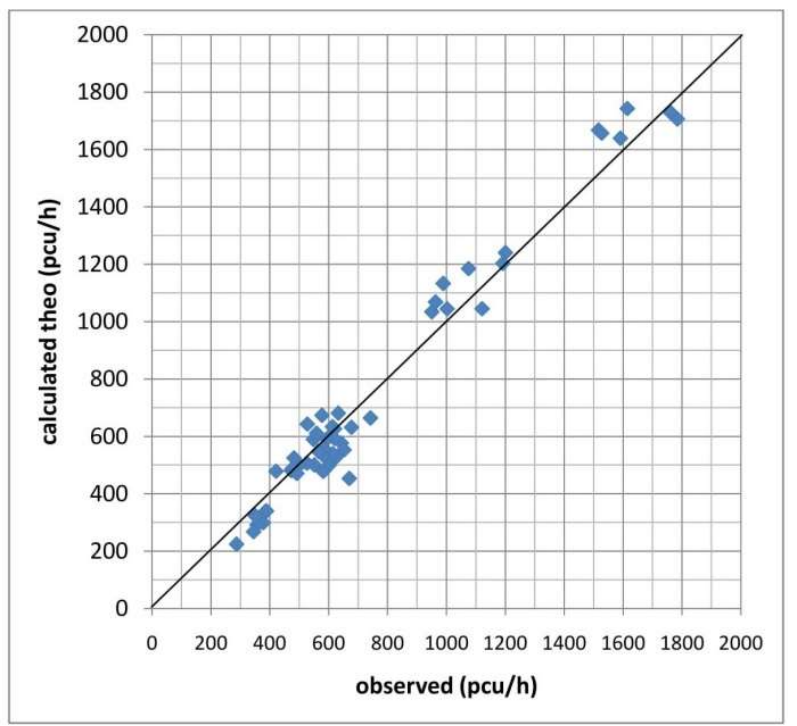

Figure 3: Theoretical vs Observed capacities

Furthermore, a simulation program was developed with assumptions which are broadly similar to actual situations in order to be realistic and to generate data which are comparable to actual field data. After checking the correctness of the logic of the simulation program and the outputs, for boundary limits and specific situations, the program was run with the actual traffic and signals settings parameters recorded in the 
field in the course of this study to test the validity of the simulation procedure against actual data. Figure 4 shows a plot of calculated against simulated data. As it can be seen on this figure, the simulation gave results which are in a fairly good agreement with experimental observations. Further, a paired t-test indicated that the differences are not statistically significant at the $95 \%$ level of confidence significance. This is a further means of validation of the proposed model if there were a need for it.

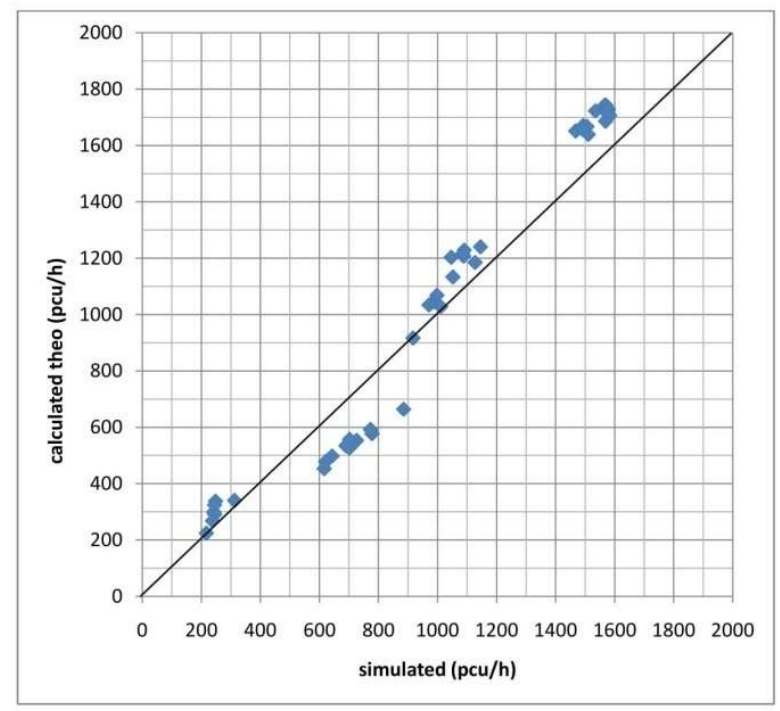

Figure 4: Theoretical vs Simulated capacities

Remarks:

1. Using the HCM notations, in equation 4 above, for $\mathrm{K}=0$, i.e. the first left turner blocks the lane one retrieves equation 7 fixing the upper limit of green time.

2. The comparison between calculated capacities with HCM method and the proposed model (figure 5) shows differencies of the same level like those obtained when comparing observed to calculated (figure 1). In this case also, the differences are statistically significant at the $95 \%$ level of confidence. 


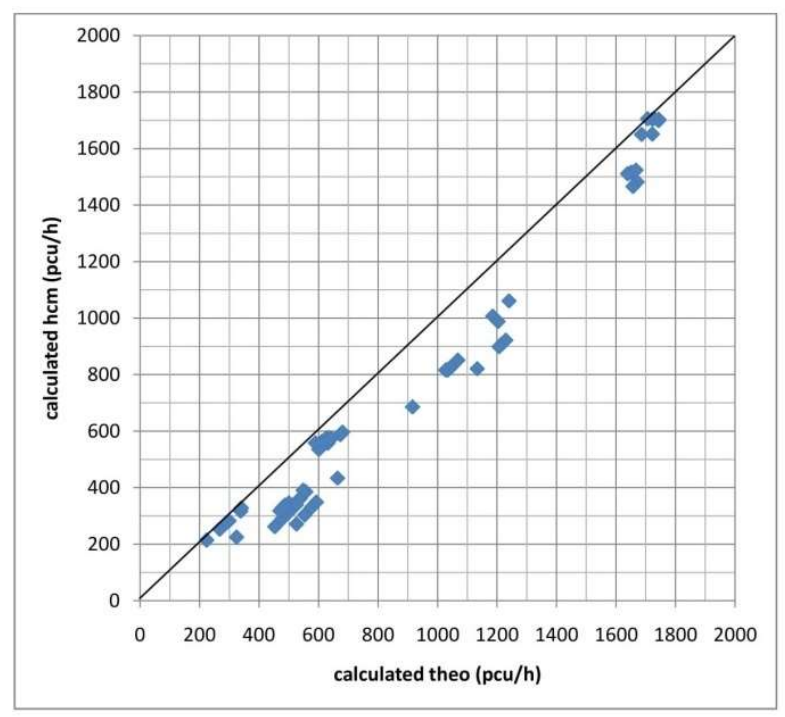

Figure 5: Theoretical vs HCM 2010 model capacities

Figures 6 and 7 represent results to illustrate the effects of different green time settings, waiting spaces and proportions of left-turners on shared lane capacity for an opposing flow $\mathrm{q}=500 \mathrm{veh} / \mathrm{h}$ and cycle time

$\mathrm{c}=2 \mathrm{~g}+8$ secs.

a)

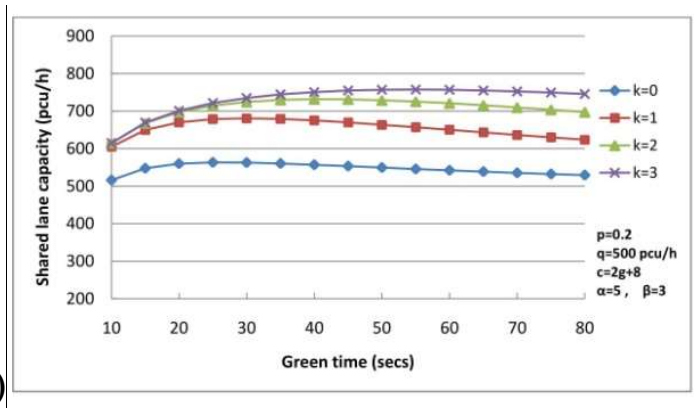

b)

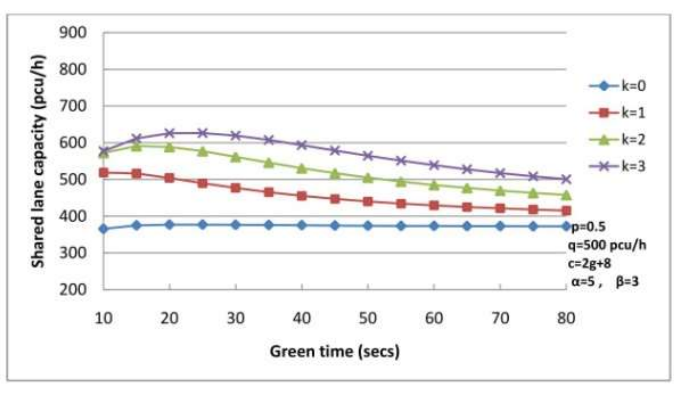

Figure 6: Shared lane capacity vs Green time for different k

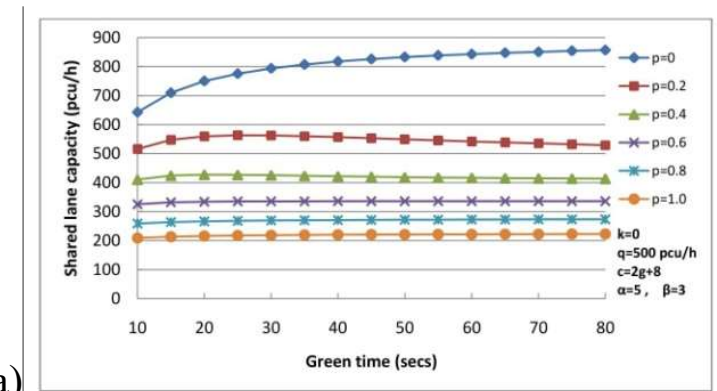

b)

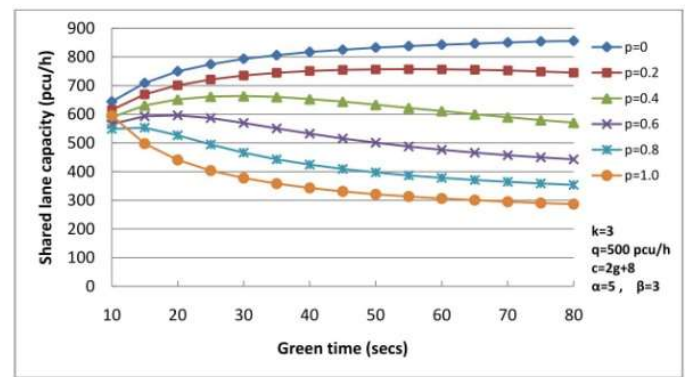

Figure 7: Shared lane capacity vs Green time for different $p$ 


\section{Conclusion:}

With oil price increase, Algeria experienced a rapid growth of car ownership which has doubled in a decade period. As flow levels increased, Engineering and design offices face a problem since there is no Algerian official manual dealing with signalized intersections studies and only foreign methods are used, without checking their appropriateness for Algerian context. This is, particularly, noticeable in city centres where the majority of streets are only 6-7 meters wide. As part of a research project, aimed at elaborating a capacity guide for signalised intersections in Algerian traffic and environment prevailing conditions, this work presents a probabilistic model developed for calculating the capacity of shared left-turn lanes with an opposing traffic flow at traffic signals controlled intersections.

The probabilistic model presented in this paper satisfactorily estimates the capacity of left-turn/straight ahead shared lanes with an opposing traffic flow at traffic signals controlled intersections. It provides a good description of vehicles interaction for a shared lane involving a proportion of left-turning vehicles, a variable number of waiting spaces $\mathrm{k}$ within the intersection for waiting turners without blocking the lane and an opposing flow.

The model was tested against data collected at 6 sites $\mathrm{k}=1$ to 5 spaces available for waiting left turners k within the intersection, without blocking the lane. Different two-phase signal settings operating on fixed time basis were implemented. The proportion of left turners in the subject lane varied from $9 \%$ to $100 \%$ and the degree of saturation of the opposing stream varied from $0.38 \%$ to $0.99 \%$. Paired t-tests were performed and the differences between observed and calculated values were not statistically significant at the $95 \%$ confidence level.

Even if the expressions of the model seem to be tedious they can, easily, be computed with a simple computer program and can be simplified for currently existing intersection layouts $(\mathrm{k}=0$ to $\mathrm{k}=3)$.

\section{References:}

- AntanasKlibavičius and GražvydasMykolasPaliulis(2012) "Increasing the capacity of intersections by short traffic lanes", Volume 27/1, pp 67-72 Dept of Urban Engineering, Vilnius Gediminas Technical University, Saulètekio al. 11, LT-10223, Vilnius, Lithuania.

- Arash Mazaheri, Amir Masoud Rahimi (2017) "Determining a suitable position for U-turns near signal-controlled road junctions. Proceedings of the institution of civil engineers - Transport

- Bang, K.L.(1978) "Swedish capacity manual", Part 3: capacity of signalised intersections, transpRes rec.667, pp 11-20.

- Brahimi K. (1989) "some factors relating to saturation flow at traffic signal controlled intersections" PhD thesis, University of Sheffield, UK.

- Brahimi K. and Ashworth R. (1992) "A theoretical model for permissive left turn capacity of shared lanes with an opposed flow at traffic signals". Proceedings of a conference on mathematics in Transport planning and control held in Cardiff, 
September 1989. The institute of mathematics and its applications: Oxford University Press, New York.

- Chapter 31/signalized intersections: supplemental of July 2012 (HCM2010).

- D. Županović, M. Anžek, G. Kos: “Optimisation of Signal-controlled Intersection capacity". Promet - Traffic\&Transportation, Vol. 22, 2010, No. 6, 419-431

- Handbuch für die Bemessung von StraBenverkehrsanlagen (German Highway Capacity Manual (HBS 2001). Forschungsgesellschaft für StraBen-und Verkehrswesen (Hesg.),Nt 299, FgsvVerglag GmbH, Köln.

- Hussein A. Ewadh, Sahar S. Neham NOV 2011 "Conflict to study safety at four leg-signalised intersections" .proceedings of the institution of civil engineers Transport

- Kimber, R.M et al (1986) "the prediction of saturation flows for road junctions controlled by traffic signals". TRRL Research report 67, Crowthorne, UK.

- Prathapan Preethi, Rajamma Ashalatha (FEB 2019) "Estimation of saturation flow under heterogeneous traffic conditions" proceedings of the institution of civil engineers - Transport.

- RAHMI AKCELIK (MARCH 1988) "The Highway Capacity Manual Delay Formula for Signalized Intersections". ITE Journal.

- Satyajit Mondal, Vijai Kumar Arya, Ankit Gupta (APR 2019) “An optimised approach for saturation flow estimation of signalised intersections" proceedings of the institution of civil engineers - Transport

- Smruti Sourava Mohapatra, Partha Pratim Dey, Satish Chandra (AUG 2016) "Conflicting volume for U-turns at uncontrolled median openings".

Proceedings of the institution of civil engineers - Transport

- Teply et al (2008): "Canadian capacity guide for signalised intersections". Institute of transportation engineers ITE district 7-canada.

- Transportation Research Board (1985) "Highway Capacity Manual" TRB Special Report 209, Washington D.C.

- Transportation Research Board (2010) "Highway Capacity Manual" TRB 5th edition. Washington D.C.

- W. Wu et al.:"CCapacity Matching Based Model for Protected Left Turn Phases Design of Adjacent Signalized Intersections Along Arterial Roads". Promet Traffic\&Transportation, Vol. 27, 2015, No. 1, 13-21.

- Wu N. (2010) "modelling blockage probability and capacity of shared lanes at signalized intersections" Institute for traffic engineering.Ruhr-University Bochum, 44780 Bochum, Germany.

- Yao R. and Michel Zhang H. (2013) "optimal allocation of lane space and green splits of isolated signalised intersections with short left-turn lanes" Journal of transportation Engineering Volume 139/7 (july2013).

- Zhao Yang, Pan Liu, Zong Z. Tian, and Wei Wang:"Evaluating the Operational Impact of Left-Turn Waiting Areas at Signalized Intersections in China". Transportation Research Record: Journal of the Transportation Research Board, No. 2286, Transportation Research Board of the National Academies, Washington, D.C., 2012, pp. 12-20. 
European Transport $\backslash$ Trasporti Europei (2020) Issue 78, Paper n 4, ISSN 1825-3997

- Zhili Tian (SEP 2002) "Capacity Analysis of Traffic-Actuated Intersections". Master of Science in Transportation. Massachusetts Institute Of Technology. 